\title{
Análise do perfil de catadores de materiais recicláveis do município de Laranjeiras do Sul, Paraná
}

\author{
Analysis of the profile of recyclable waste pickers in the municipality of \\ Laranjeiras do Sul, Paraná

\section{Análisis del perfil de recolectores de material reciclable en el municipio de Laranjeiras do Sul, Paraná}

\author{
Grasieli de Fátima Rode ${ }^{1}$ \\ Janete Stoffel ${ }^{1}$ \\ Gabriela Silva Moura ${ }^{1}$
}

\begin{abstract}
Resumo: O trabalho teve o objetivo de analisar o perfil de catadores de materiais recicláveis do município de Laranjeiras do Sul, Paraná, Brasil, e relacionar com a teoria de privação de liberdades de Amartya Sen. A identificação do perfil dos catadores de materiais recicláveis se deu a partir de um levantamento de dados primários, por meio de entrevistas. A pesquisa é caracterizada como estudo de caso e foi construída a partir de levantamento bibliográfico, utilizando os métodos descritivo e explicativo, com abordagem quantiqualitativa. Os resultados, mostraram que os catadores convivem com inúmeras privações de liberdades, tais como: baixa escolaridade e renda; idade avançada sem acesso à seguridade social; falta de documentos para acesso a direitos fundamentais; privações que limitam o alcance de um nível mínimo de condições de vida.
\end{abstract}

Palavras-chave: reciclagem; catador; privação; liberdade.

Abstract: This study aimed to analyze the profile of recyclable waste pickers in the municipality of Laranjeiras do Sul, Paraná, Brazil, and to relate to Amartya Sen's deprivation of liberty theory. The identification of the profile of recyclable waste pickers occurred from a survey of primary data through interviews. The research is characterized as a case study and was constructed from a bibliographical survey, using descriptive and explanatory methods, with a quantitative and qualitative approach. The results showed that the waste pickers coexist with numerous deprivations of freedoms, such as low schooling and income; advanced age without access to social security; lack of basic documents for fundamental rights access; deprivations that limit the reach of a minimum level of living conditions.

Keywords: recycling; waste pickers; privation; freedom.

Resumen: El estudio tuvo como objetivo analizar el perfil de recolectores de materiales reciclables en el municipio de Laranjeiras do Sul, Paraná, Brasil, y relacionarlo con la teoría de la privación de libertad de Amartya Sen. A partir de una encuesta de datos primarios, a través de entrevistas. La investigación se caracteriza como un estudio de caso y se construyó a partir de una encuesta bibliográfica, utilizando métodos descriptivos y explicativos, con un enfoque cuantitativo y cualitativo. Los resultados mostraron que los recolectores viven con numerosas privaciones de libertad, tales como: baja educación e ingresos; vejez sin acceso a la seguridad social; falta de documentos para acceder a los derechos fundamentales; privaciones que limitan la consecución de un nivel mínimo de condiciones de vida.

Palabras clave: reciclaje; recolector; privación; libertad.

\section{INTRODUÇÃO}

Uma das atividades mais antigas da humanidade é a de catar sobras de alimentos para sobreviver. Esta atividade vai muito além de uma estratégia de sobrevivência, já que adquire o formato de trabalho, gerando renda para uma parcela da população social e economicamente marginalizada (BOTELHOL et al., 2017).

\footnotetext{
${ }^{1}$ Universidade Federal da Fronteira Sul (UFFS), Laranjeiras do Sul, Paraná, Brasil.
} 
Até a década de 1980, a presença de pessoas que coletavam resíduos era destacada principalmente por poetas e dramaturgos. O poeta Manuel Bandeira, em 1947, em sua obra "O Bicho", já apresentava relatos de pessoas que coletavam alimentos no lixo para sobreviver. Mas, ainda assim, Bandeira não se referia necessariamente a catadores de materiais recicláveis, e sim às pessoas que vasculhavam o lixo em busca de alimentos (BOSI, 2008).

Trinta anos após a obra "O Bicho", Plínio Marcos retoma os relatos de Manuel Bandeira e escreve a peça de teatro "Homens de Papel" (1978). Nesta peça, o autor cita que realizavam a coleta de materiais recicláveis e atuavam como trabalhadores, concentrados nas cidades grandes (BOSI, 2008). Fora da dramaturgia, a realidade se apresenta mais dura, uma vez que a coleta dos materiais é tarefa árdua, realizada pelos chamados segregados do convívio social, pessoas idosas, doentes, entre outras. Além disso, por muito tempo, os catadores estiveram submetidos a representações como lixeiros, homem do saco, garrafeiro, palavras estas que, se dicionarizadas, trazem denominações pejorativas à pessoa do catador e à atividade que desempenha (WADMAN, 2010).

A expansão da visibilidade do trabalho dos catadores foi possibilitada, em parte, pelo aumento no tamanho dessa população. Na década de 1980, os catadores de materiais recicláveis tornaram-se mais visíveis como força de trabalho numericamente significativa e, em consequência, passaram a realizar a reciclagem em maior escala (BOSI, 2008).

Segundo Magalhães (2012), os catadores de materiais recicláveis vivem à margem do mercado de trabalho, em condições de exclusão social, encontrando na catação dos recicláveis uma fonte de renda. Entretanto esta alternativa comumente não se consolida como uma condição digna de ocupação para obter a renda necessária e suficiente para dar conta das demandas individuais e da família. É nesse contexto que desemprego estrutural, precarização do trabalho, baixa renda e pouco acesso à saúde, escolaridade e moradia configuram-se na privação de liberdade dos sujeitos identificados como catadores.

Magera (2003) e MNCR (2010) mencionam que os catadores de materiais recicláveis no Brasil vivenciam privações de liberdade a partir das múltiplas carências as quais estão submetidos, tais como pouca renda, falta de oportunidades e privação de direitos. Essas carências Ihes tomam a liberdade e ainda impedem que alcancem adequadas condições de vida e níveis satisfatórios de desenvolvimento.

A realidade dos catadores de materiais recicláveis é mais triste do que o papel de agentes ecológicos que muitos Ihes atribuem. Estes trabalhadores convivem diariamente com a exclusão social, que é reforçada pelo preconceito proveniente da atividade, além de sua atuação estar relacionada com o que é descartado pela sociedade: o lixo. E, apesar de ter havido crescimento na formalização deste trabalho, via organizações coletivas, na maior parte das vezes, o trabalho dos catadores é informal.

A perspectiva fundamentada na liberdade, destacada por Sen (2010), valoriza o modo como as pessoas vivem, as escolhas que podem fazer diante das oportunidades que existem, e não apenas no poder aquisitivo que elas detêm. Para o autor, a liberdade é importante para o desenvolvimento por dois motivos: avaliação e eficácia.

Ter maior liberdade corresponde à existência de oportunidades para realizar coisas que são valorizadas, para que se consiga obter resultados valiosos. A liberdade é capaz de transformar o potencial das pessoas para cuidar de si mesmas e intervir no mundo em que vivem. Mas, para que as pessoas consigam exercer de forma positiva esta liberdade, são influenciadas por 
oportunidades econômicas, liberdades políticas, poderes sociais, condições de aptidão, como boa saúde, incentivo, aprimoramento de decisões e educação básica (SEN, 2010).

A partir deste contexto, a presente pesquisa teve o objetivo de conhecer e analisar o perfil dos catadores de materiais recicláveis do município de Laranjeiras do Sul, Paraná (PR). A partir deste diagnóstico, relaciona as condições observadas com a perspectiva teórica do dilema de privação de liberdades de Amartya Sen.

\section{METODOLOGIA}

A pesquisa que resultou neste artigo foi realizada no município de Laranjeiras do Sul, Paraná, durante o ano de 2015. Ela é caracterizada como estudo de caso e foi construída a partir de levantamento bibliográfico realizado em livros, artigos, dissertações e teses. Foram utilizados os métodos descritivo e explicativo, com abordagem quantiqualitativa.

Os sujeitos pesquisados foram vinte e dois catadores de materiais recicláveis, escolhidos por meio do método da bola de neve. Neste processo, buscou-se um primeiro respondente a ser pesquisado; este, após responder o questionário, indicava o próximo respondente, e assim sucessivamente.

As entrevistas foram realizadas no período de maio a novembro de 2015, com aplicação de dois questionários como pré-teste. Após a aplicação desses, constatou-se a necessidade de acrescentar questões e modificar o texto, facilitando o entendimento para possibilitar maior compreensão aos entrevistados sobre o que estava sendo indagado.

Na pesquisa de campo, foram efetuadas questões aos entrevistados sobre: idade, sexo, estado civil, escolaridade dos catadores e dos filhos, tamanho das famílias, número de filhos, renda total, renda proveniente dos materiais recicláveis, renda advinda de programas sociais, situação da moradia. No questionário, constavam ainda perguntas para identificar rotina de trabalho e preferências, dificuldades encontradas na atividade, satisfação obtida a partir do serviço realizado, quantidade de materiais coletados por mês, manipulação destes materiais e a predisposição dos pesquisados em participar de organizações associativas e cooperativas.

A análise dos dados foi realizada por meio de um comparativo das respostas entre os entrevistados, no sentido de averiguar situações similares vividas pelos catadores. A amostra por conveniência, adotada nesta pesquisa, é do tipo não probabilística, por isso não permite a generalização dos resultados obtidos.

\section{RESULTADOS E DISCUSSÃO}

Dos 21 catadores de materiais recicláveis, 13 eram homens, correspondendo a 64\% dos entrevistados. Em termos de estado civil, constatou-se que $82 \%$ dos entrevistados disseram ser casados. Em relação à idade, a média dos respondentes é de 47,5 anos, sendo que $60 \%$ dos entrevistados mencionou idade entre 50 e 54 anos. O catador mais idoso tinha 69 anos, e o mais jovem, 27 anos. Nestes dados, é possível constatar que, no grupo dos catadores, há desde jovens até idosos desenvolvendo a atividade.

Quanto aos catadores mais idosos, esses justificam seu trabalho de coleta dos recicláveis como sendo uma complementação à renda e, também, como forma de ocupação para o tempo que dispõem. Entretanto, para Silva et al. (2011), esse fato é reflexo da falta de espaço para estes indivíduos no mercado de trabalho, tendo em vista a grande dificuldade de emprego para 
pessoas idosas. Já no caso dos mais jovens, a atuação nesta atividade indica que, no momento da pesquisa, a ocupação formal não era uma realidade para este(s) indivíduo(s).

Em relação às condições de assistência social, os dados obtidos na pesquisa revelam que 59\% dos entrevistados nunca contribuíram para a previdência social. Entre aqueles que contribuíram, isto aconteceu enquanto trabalhavam formalmente em empresas. No momento da pesquisa, nenhum dos catadores estava contribuindo para a previdência social. O fato de não serem contribuintes resulta em consequências como: não poder usufruir de benefícios por problemas de saúde, licença-gestante, aposentadoria. Diante disto, considerando que a maior parte dos entrevistados já ultrapassou a faixa etária de 50 anos, constata-se que o futuro desses trabalhadores provavelmente será sem tipo algum de segurança social.

No caso dos jovens e adultos, foram encontradas semelhanças entre os motivos que justificam a "opção" pela profissão de catador de materiais recicláveis. Entre os pesquisados, observou-se que $25 \%$ dos catadores jovens e adultos sofreram algum tipo de acidente, o qual comprometeu sua condição física, dificultando e até mesmo impedindo o acesso ao mercado formal de trabalho. Verificou-se que $10 \%$ dos entrevistados sofrem de transtornos psicológicos, outro fator apontado como limitador para obtenção de trabalho formal. Segundo Kirchner, Saidelles e Stumm (2009), o desemprego, a idade, a condição social e a baixa escolaridade são fatores-chave que influenciam na escolha da coleta de materiais recicláveis como atividade profissional.

Outro aspecto observado foi um elevado percentual de catadores que não possuem documentos de identificação. Do total de entrevistados, 37\% não possuem carteira de trabalho. Alguns dos motivos apontados para a ausência deste documento são o extravio associado ao desinteresse em fazê-lo. Nos relatos apresentados a seguir, constam algumas ilustrações sobre o que foi alegado pelos pesquisados para a inexistência deste documento: "Perdi nas mudanças e outra parte molhou" (homem, 46 anos); "Perdi e não quis fazê outra" (mulher, 32 anos); "Perdi e não tem muita obrigação de tê, por isso não fui mais atrás" (homem, 59 anos); "Nunca me interessei em fazê" (mulher, 44 anos).

Observou-se que, na ausência da posse dos documentos, as alegações recaíram sobre extravio ou roubo. Além da falta de carteira de trabalho, observou-se ainda que, entre os entrevistados, $27 \%$ não possuem certidão de nascimento, 23\% afirmaram não possuir título de eleitor, $13 \%$ não têm CPF e $9 \%$ não possuem carteira de identidade. Ao serem questionados sobre a possibilidade de refazer os documentos, alguns não manifestaram este interesse, acreditando que isto seja desnecessário. A realidade observada em relação à baixa disponibilidade de documentos entre os catadores é preocupante, pois, oficialmente, estas pessoas não existem nas instâncias nas quais os documentos são considerados. Em decorrência disso, ficam excluídas de exercer seus direitos ou de acessar benefícios, ou seja, vivenciam efetivamente a privação de liberdades em termos de direitos civis.

Outro documento bastante importante e que poderia oferecer oportunidades profissionais é a Carteira Nacional de Habilitação (CNH). Ao serem questionados sobre a posse de $\mathrm{CNH}$, constatou-se que $100 \%$ dos entrevistados não possuem habilitação para conduzir veículos. Alguns dos motivos que impediram os entrevistados de adquirir a CNH estão destacados nas falas a seguir: "Não tenho dinheiro pra fazê e nem estudo" (homem, 53 anos); "Não deu certo de fazê ainda, tá faltando dinheiro" (homem, 43 anos); "Não tenho estudo pra isso" (homem, 59 anos); "Não tenho condição de compra um carro, rende pouco os material" (homem, 27 anos); "Nunca me interessei em fazê" (mulher, 44 anos); "Nunca quis fazê, eu nem sei dirigi" (mulher, 32 anos). 
Em relação à $\mathrm{CNH}$, constata-se que a posse de tal documento é uma realidade muito distante dos catadores de materiais recicláveis em Laranjeiras do Sul, Paraná. A ausência de posse deste documento distancia ainda mais estes sujeitos das oportunidades de emprego, consistindo em uma segunda privação de liberdade vivenciada pelos catadores.

No que tange à escolaridade dos entrevistados, constatou-se que, do total de entrevistados, $68 \%$ não concluíram o ensino fundamental, $27 \%$ são analfabetos e apenas $5 \%$ concluíram o ensino fundamental. Esta baixa escolaridade, aliada à ausência de capacitações, está também relacionada à falta de oportunidades que o mercado de trabalho oferece a esses indivíduos. Neste aspecto, a baixa escolaridade é característica peculiar de outros estudos envolvendo catadores no restante do Brasil (MAGERA, 2003; KIRCHNER; SAIDELLES; STUMM, 2009; SILVA et al., 2011).

A situação de baixa escolaridade e a ausência ou ineficaz capacitação dos catadores podem dificultar a transformação da realidade em que se encontram esses indivíduos e, também, de seus filhos. Outro dado importante e preocupante é o percentual de analfabetos ( $27 \%$ do total), situação que acentua ainda mais suas carências na sociedade. Neste ínterim, Magera (2003) evidencia que a baixa escolaridade pode ser um dos impulsos que levam estas pessoas à condição de catadores, e, ao serem catadores, sofrem também a exploração de atravessadores.

Quanto aos motivos que impediram os catadores pesquisados de concluir o ensino médio, foram observadas semelhanças entre as respostas. Foram mencionados: proibição dos pais, tendo em vista que a prioridade era o trabalho; e a longa distância entre a escola e o domicílio. Em geral, as falas dos catadores evidenciam uma dura história de vida, na qual deixaram de estudar, pois não havia condições de conciliar estudo e sobrevivência: "A escola era longe da casa, a gente só sabia trabalha, o estudo ficava de lado, porque a gente precisava sobreviver" (homem, 46 anos); "Muitas vez tinha que fica só trabalhando, não dava nem de ir pra aula" (mulher, 51 anos); "Um pouco era porque a escola era longe, tinha que lidar, na enxada, roçada. E outra parte era que não tinha roupa e carçado pra i na aula" (homem, 39 anos).

Conforme salienta Sen (2010, p. 124), "Quanto mais inclusivo for o alcance da educação básica [...], maior será a probabilidade de que mesmo os potencialmente pobres tenham uma chance maior de superar a penúria". A necessidade de escolher entre estudar e sobreviver ilustra a privação de liberdade que estes indivíduos carregam em sua trajetória de vida.

Em relação ao número de filhos, os 22 entrevistados possuem um total de 101 filhos, sendo que, em média, cada entrevistado tem 4,59 filhos. Do total de entrevistados, $36 \%$ possuem de 3 a 4 filhos; 32\%, de 5 a 6 filhos; 9\%, de 1 a 2 filhos; 9\%, de 9 a 10 filhos; 5\%, de 7 a 8 filhos; e $5 \%$ possuem acima de 11 filhos. Sen (2010) associa a educação e o emprego feminino como fatores que influenciam diretamente nas taxas de fecundidade. Assim, mulheres com maior grau de instrução tendem a ter menos filhos e, como já relatado, o grupo de catadores entrevistados nesta pesquisa apresenta baixos níveis de escolaridade.

No que tange à escolaridade dos filhos dos entrevistados, aqueles que frequentam ou frequentaram a escola o fizeram em escola pública. Evidenciou-se que $26 \%$ dos filhos não concluíram o ensino fundamental; dentre esses, 62\% continuam estudando, $10 \%$ não concluíram o ensino médio, $5 \%$ possuem o ensino fundamental completo e apenas $3 \%$ possuem o ensino médio completo.

A baixa porcentagem de filhos que concluem o ensino médio se deve à baixa renda das famílias; com isso, os jovens começam a trabalhar cedo, prejudicando a continuidade dos estudos. No caso das filhas, algumas engravidaram durante o período escolar e, por este 
motivo, abandonaram a escola. Infelizmente, nestes casos, os filhos estão dando continuidade à dura realidade na qual seus pais foram criados, ou seja, sem acesso a melhores condições de escolarização. Esses fatores podem contribuir para que a pobreza e a privação de liberdades se mantenham dentro da família.

Com relação ao total de pessoas que residem no mesmo domicílio, observou-se que em $50 \%$ dos casos há entre 4 e 6 pessoas na casa; em 41\% dos domicílios pesquisados, residem entre 1 e 3 pessoas; e, em 9\% dos domicílios, residem acima de 7 pessoas. No que tange à situação das moradias, 59\% dos entrevistados informaram que estas foram cedidas pelo governo municipal; $32 \%$ encontram-se em situação de moradia própria e quitada; e 9\%, alugada. Cabe ressaltar que $13 \%$ dos respondentes residem em áreas invadidas, em terrenos que ainda estão irregulares (e estão aguardando a regularização pelo governo municipal), mas informaram que a situação do domicílio é cedida.

Outros catadores estão com suas residências em situação de regularização pela prefeitura. Estes responderam que sua moradia se encontra em situação cedida, mas na verdade estão em trâmite de regularização, pois ocuparam áreas clandestinamente.

Em relação aos rendimentos dos entrevistados, constatou-se na pesquisa que o valor médio da renda familiar mensal correspondia a $\mathrm{R} \$ 750,18$ (setecentos e cinquenta reais e dezoito centavos), ou seja, menos de um salário mínimo². Há catadores que informaram receber entre um e dois salários mínimos, sendo estes os casos em que, no grupo familiar, há pessoas que recebem benefícios, como Bolsa Família e auxílio-doença. Não foram encontrados catadores que recebem acima de dois salários mínimos ${ }^{3}$. Em relação à renda proveniente dos materiais recicláveis, observa-se que, para $46 \%$ dos entrevistados, ela corresponde à principal renda, representando mais de $60 \%$ da renda total.

Sobre a renda total disponível na unidade familiar, do total de entrevistados, $41 \%$ informaram que possuem renda entre 1 e 2 salários mínimos. Em relação a este grupo, é importante destacar que, em $88 \%$ dos domicílios, há pessoas que recebem benefício por aposentadoria ou auxíliodoença, contribuindo para a elevação na renda familiar. Relacionando o percentual de domicílios em que a renda familiar máxima é de um salário mínimo com o percentual de domicílios nos quais residem mais de 4 pessoas, tem-se que estes dois correspondem a 59\%. Isso ajuda a ilustrar realidades financeiras restritivas nas quais a renda não é suficiente para suprir as necessidades básicas dos integrantes da família. Nas palavras de Sen (2010, p. 124), “[...] a renda é um meio importantíssimo de obter capacidades", sendo que, nas famílias em que houver crianças, pessoas incapazes ou doentes, a capacidade de auferir renda estará ainda mais comprometida.

Para averiguar o nível de pobreza em que se encontram os catadores de materiais recicláveis do município de Laranjeiras do Sul, PR, foi considerado o cálculo utilizado pelo Programa Bolsa Família, para a concessão das bolsas: a renda total familiar dividida pelo número de pessoas que moram no domicílio (PORTAL BOLSA FAMÍLIA, 2015). A partir do resultado, tem-se que os catadores com renda familiar per capita inferior a $\mathrm{R} \$ 154,00$ mensais são famílias que estão

\footnotetext{
${ }^{2}$ O valor do salário mínimo considerado nesta pesquisa corresponde ao vigente em outubro de 2015, que era de $\mathrm{R} \$ 788,00$.

${ }^{3} \mathrm{~A}$ renda total familiar corresponde à renda total de todos os residentes no domicílio do catador. Esta renda corresponde à soma da renda dos recicláveis, com as rendas oriundas de outras atividades, benefícios, pensão, Bolsa Família etc.
} 
em situação de pobreza ${ }^{4}$. No cálculo sobre o nível de pobreza, constatou-se que, em $63 \%$ dos domicílios pesquisados, a renda é inferior a $\mathrm{R} \$ 200,00$ por morador. Nos domicílios em que os valores per capita superam os $\mathrm{R} \$ 300,01$ mensais, cabe ressaltar que ali residem pessoas com acesso aos benefícios, como o Programa Bolsa Família, aposentadoria ou auxílio-doença.

Segundo Sen (2010, p. 121), "[...] pessoa mais velha, mais incapacitada ou mais gravemente enferma, em geral necessita de mais renda (para assistência, prótese ou tratamento)". Assim, naqueles domicílios em que a renda per capita é maior, quando há na família idosos ou pessoas enfermas, a pobreza real das famílias pode ser mais significativa do que aparenta ser em termos monetários.

Em relação ao acesso ao Programa Bolsa Família, do governo Federal, constatou-se que a maioria dos catadores entrevistados, $55 \%$ do total, possui a inscrição no programa ${ }^{5}$. Os catadores que são beneficiados recebem, por meio deste programa, um valor mensal de aproximadamente $\mathrm{R} \$ 149,92$. Entretanto 45\% dos entrevistados afirmaram não ter acesso ao Programa, e, tendo em vista que a renda familiar per capita está dentro dos índices de quem teria direito a ser atendido por este benefício, constata-se que há problemas de acesso e, assim, destaca-se mais uma privação à qual este grupo está exposto. Os motivos que podem ter suscitado a não participação dos catadores seriam decorrentes da falta de informação, da falta de documentos de identificação, de filhos que abandonaram a escola ou do não atendimento às condicionalidades previstas no artigo 3으 da Lei 10.836/2004.

Quando os entrevistados foram questionados sobre perspectivas favoráveis para suas vidas, constatou-se que eles não acreditam que isto seja possível. Vivendo sob condições de baixa escolaridade e baixa renda, eles se veem isolados, carentes de reconhecimento, sentem-se esquecidos pela sociedade e não conseguem vislumbrar alternativas melhores para a vida, além da atividade que exercem. Em geral, eles não veem problemas na função de serem catadores e não se sentem capazes de conseguir oportunidades melhores. Aliás, o que se pôde perceber é que, a cada dia, estes catadores têm de reinventar suas estratégias de sobrevivência.

A maior parte das entrevistas aconteceu na residência dos catadores, sendo possível observar que sobrevivem com poucos recursos e que, em geral, nem as necessidades básicas conseguem suprir. A condição de privação de liberdade a que estão submetidos os catadores é a barreira que impede esses indivíduos de obterem melhores condições de vida. Conforme aponta Sen (2010, p. 76), "[...] a expansão da liberdade humana é tanto o principal fim como o principal meio do desenvolvimento", permitindo concluir que os catadores, ao não alcançar melhores perspectivas, estão limitados também no alcance de níveis mais elevados de desenvolvimento.

Em termos de organização do trabalho, a maioria dos catadores afirmou desempenhar sua função de catador de forma individual. Manifestaram preferência por esta forma para não se comprometer ou para não ter de dividir sua coleta com outras pessoas. Entre os pesquisados, cabe destacar que $45 \%$ dos entrevistados já fizeram parte de associação de catadores. Estes informaram

\footnotetext{
${ }^{4}$ O primeiro valor da escala (inferior ou até $\mathrm{R} \$ 154,00$ ) foi estabelecido conforme o parâmetro utilizado pelo Programa Bolsa Família, no qual as famílias consideradas pobres são aquelas que recebem o valor inferior a R\$154,00/mês por morador (PORTAL BOLSA FAMÍLIA, 2015).

${ }^{5}$ A concessão dos beneficiários dependerá do cumprimento, no que couber, de condicionalidades relativas ao exame pré-natal, ao acompanhamento nutricional, ao acompanhamento de saúde, à frequência escolar de $85 \%$ (oitenta e cinco por cento) em estabelecimento de ensino regular para crianças com idade entre 0 (zero) e 12 (doze) anos ou adolescentes até 15 (quinze) anos. Já para os adolescentes, com idade entre 16 e 17 anos, é exigida a frequência mínima de 75\% às aulas, sem prejuízo de outras previstas em regulamento (BRASIL. LEI 10.836/2004, Art. 3으).
} 
que deixaram de compor a associação por motivos como: falta de transparência nas informações; pagamento quinzenal dos materiais; associados alcoolizados que atrapalhavam o andamento das atividades e provocavam brigas; desentendimentos com o presidente da associação. Foi possível constatar nas entrevistas um descrédito de que este tipo de empreendimento possa lhes trazer sucesso, principalmente em decorrência das experiências negativas pelas quais afirmaram ter passado.

Entretanto, apesar das experiências negativas relatadas por vários catadores, em relação à vivência associativa, alguns dados da pesquisa demonstram que há condições mais favoráveis para aqueles que participam deste grupo coletivo. Um destes dados corresponde à renda média obtida a partir da venda de materiais recicláveis coletados. Constatou-se que os pesquisados vinculados à associação de catadores existente no município possuem renda superior no comparativo com aqueles que vendem o material de forma individual.

Muitos dos catadores de materiais recicláveis entrevistados estão excluídos de oportunidades sociais, sendo estas extremamente importantes na expansão das capacidades humanas e da qualidade de vida desses indivíduos. Com base em Sen (2010, p. 191), "A expansão dos serviços de saúde, educação, seguridade social etc. contribui diretamente para a qualidade de vida e seu florescimento". O autor destaca o fato de que, apesar de os indivíduos apresentarem rendas relativamente baixas, quando um país/estado/município garante $(\mathrm{m})$ oportunidades sociais, como serviços de saúde, assistência, educação, as consequências na qualidade de vida da população são atenuadas.

Outra observação efetuada na pesquisa foi a de conhecer o tempo em que os catadores estão na atividade de coleta de materiais recicláveis. Observou-se que 4,83\% do total de entrevistados trabalhavam como catadores há mais de 5 anos. Retomando o fato de que metade dos catadores tem idade superior a 50 anos, tem-se um cenário de dificuldades para a obtenção de emprego dessas pessoas. Em relação às ocupações que tinham antes de se tornarem catadores de materiais recicláveis, observou-se que: $27 \%$ eram funcionários de empresas; $23 \%$ eram agricultores; $23 \%$, boias-frias; $14 \%$ foram pedreiros; $5 \%$, pintores; $5 \%$, zeladores; e $5 \%$, cozinheiros.

Em relação à atuação dos pesquisados na atividade de catador, observou-se que 22,73\% do total de entrevistados relataram ter descontinuado a coleta dos recicláveis por diversas vezes. Ou seja, deixaram de atuar na coleta de materiais reciclados por determinado período e, no decorrer deste tempo, desenvolveram outras atividades. As atividades mais citadas como motivo para a descontinuidade são a atuação em atividades temporárias, como a colheita de maçã, de erva-mate e o trabalho como serventes de pedreiro.

Todos os catadores de materiais recicláveis pesquisados constroem sua rotina de trabalho diária. Entre os entrevistados, 68\% trabalham todos os dias da semana, 23\% trabalham 6 dias por semana e 9\% trabalham 5 dias por semana (esse número corresponde às respondentes do sexo feminino, tendo em vista que, nos finais de semana, necessitam ficar em casa para cuidar dos filhos). Foi possível constatar também que, do total de entrevistados, 12\% afirmaram trabalhar mais de 12 horas por dia; outros 36\% alegaram trabalhar entre 8 e 12 horas por dia; 27\% trabalham entre 4 e 8 horas por dia; e 23\% trabalham menos de 4 horas por dia.

A rotina da atividade desempenhada pelos catadores é árdua, tendo em vista que exige grande esforço físico, pela necessidade de percorrer longas distâncias em busca de material, empurrando o carrinho (pesado), durante várias horas de trabalho diário. Entretanto, pelo tempo dedicado à atividade, a renda gerada é baixa e pode ser caracterizada como autoexploração. Em 
geral, a rotina diária dos catadores entrevistados se inicia cedo para evitar os horários próximos ao meio-dia, devido ao sol e calor excessivo, mas a permanência ou não na rua depende dos resultados da coleta. Esta realidade fica demonstrada em afirmações dos pesquisados: "Quanto mais cata, mais dá no final do mês, então tem que trabaiá bastante" (homem, 39 anos). Quanto aos locais em que são realizadas as coletas, observou-se que $48 \%$ delas acontecem nas ruas; $28 \%$, nos estabelecimentos comerciais; e $25 \%$, em residências.

Para o transporte dos materiais recicláveis, $86 \%$ dos catadores pesquisados utilizam-se de carrinhos que, em geral, são construídos pelos próprios catadores, com madeiras coletadas. Outros utilizam bicicletas (5\%) e carrinho de mão (de construção) (5\%). Quanto à quantidade mensal coletada, observou-se que $41 \%$ recolhem em torno de $500 \mathrm{~kg}$ de material reciclável por mês.

Constatou-se que os catadores vinculados à associação, em sua totalidade, souberam informar a quantidade mensal coletada. Entretanto todos aqueles que não conheciam esta quantidade trabalham de forma individual. A justificativa para este desconhecimento pode ser observada na fala de alguns: "Eu num sei, eles num me dão nota, só me pagam a carga, mas eu acho que é bastante" (homem, 66 anos).

Entre os materiais recolhidos pelos catadores, metal, plástico, papel e vidro respondem pelas maiores quantidades. Ou seja, pelo volume de material que coletam, percebe-se que os catadores têm papel importante na limpeza urbana do município, embora isso seja o aspecto menos importante na reflexão deste trabalho, em virtude das dificuldades e privações de liberdade que fazem parte da rotina desses indivíduos.

Conforme mencionado, grande parte dos catadores pesquisados residem nos bairros Presidente Vargas e São Francisco. Estes catadores, em sua maioria, deslocam-se até a região central do município de Laranjeiras do Sul, PR, para realizar a coleta dos recicláveis. No centro, é onde está concentrada a geração de resíduos mais nobres, em virtude da localização dos estabelecimentos comerciais que geram os materiais preferidos pelos catadores (metal, plástico, papel). Conforme calculado pelo Google Maps (2015a), a distância entre o bairro Presidente Vargas e o Centro de Laranjeiras do Sul, PR, é de 2,4 km. E a distância entre o Bairro São Francisco e o Centro é de 2,7 km (GOOGLE MAPS, 2015b). Ou seja, os dois bairros são distantes do centro, o que ilustra a dura jornada enfrentada por estes catadores, que empurram o carrinho pesado nessas distâncias entre suas residências e os locais das coletas.

O acondicionamento dos materiais ocorre da seguinte forma: os catadores vinculados a uma associação dispõem de um barracão onde podem guardar seus materiais até a comercialização. Entre os entrevistados, 4\% daqueles vinculados à associação optam por guardar os materiais coletados no quintal de casa ou em terreno baldio; os demais deixam no barracão da associação. O motivo apontado para esta opção é a distância entre a residência dos catadores e a associação.

Enquanto os catadores vinculados à associação optam, preferencialmente, por deixar os materiais neste espaço, aqueles que atuam de forma individual não têm outra opção que não seja armazenar os materiais no quintal de casa. Os materiais coletados, sobretudo aqueles que contêm restos de alimentos, provocam mau cheiro e atraem moscas. Essas condições favorecem contaminações diversas e a proliferação de doenças, além do fato de que há muitas situações nas quais ocorre a convivência desses resíduos com animais, como cachorros e gatos, aumentando as chances de disseminação de doenças. Diante deste cenário, pode-se afirmar que os catadores inseridos em associações apresentam condições de trabalho menos insalubres. 
Ao serem questionados sobre a importância do trabalho, 53\% dos entrevistados responderam ser um meio de sobrevivência para garantir uma renda extra e obter sustento para a família. Muitos, também, observam a importância ambiental no trabalho que desempenham, tendo em vista que responderam ser bom para a limpeza da cidade. Entretanto, pelas condições de vida que são obrigados a viver, não se pode falar em sustentabilidade quanto ao papel que desempenham, seja para a sociedade, seja para si próprios.

Ao serem indagados sobre as principais dificuldades enfrentadas, os catadores citaram a baixa remuneração da atividade; a exigência de elevado esforço físico; os dias chuvosos e de calor excessivo; o volume coletado, quando diminui; e o transitar pelas ruas concomitante com o fluxo de veículos no centro da cidade. Outras dificuldades relatadas ainda são a discriminação que sofrem pelo trabalho que executam, a falta de equipamentos de segurança e a fragilidade dos carrinhos de transporte de resíduos.

Apesar das condições adversas nas quais vivem os catadores entrevistados, houve alguns que responderam não sentir dificuldades no trabalho que desempenham: "Nada é dificultoso pra mim, deu de fazer eu tô fazendo. Não tem dificuldade pra gente" (homem, 53 anos). Surpreende que, apesar das condições privativas em que vivem, 55\% dos entrevistados dizem estar satisfeitos com o trabalho que desempenham. Algumas das justificativas apresentadas pelos entrevistados: "Gosto mesmo de catar! A gente é bem-visto" (homem, 53 anos). "Tem que sentir, né, é o ganho da gente, trabalhando o que pode é a conta" (homem, 29 anos). "Sim, é bom catar material, melhor que tá roubando" (mulher, 32 anos). Cabe ressaltar que estas respostas foram concedidas apesar de haver na pergunta alternativas negativas quanto ao trabalho, como insatisfeito e muito insatisfeito.

$E$, quando questionados sobre o desejo de terem outra profissão, $82 \%$ responderam que sim, gostariam de trabalhar em condições menos insalubres. Os outros $18 \%$ disseram que têm desejo de mudar de profissão, mas que acham difícil isso acontecer, porque se sentem velhos demais para enfrentar o mercado formal de trabalho.

Outra verificação em relação ao perfil dos catadores foi sobre sua propensão à organização coletiva. Neste sentido, os pesquisados foram questionados sobre sua preferência em trabalhar de forma coletiva ou individual. Do total de entrevistados, $64 \%$ responderam ter preferência por trabalhar de forma individual. Os argumentos para esta preferência podem ser observados nas falas a seguir: "Porque a hora que quer ir trabaia vai, a hora que quer voltar, não precisa pergunta é só vim" (mulher, 32 anos). "O que a gente faz é só da gente, ninguém tira" (homem, 27 anos).

Nas falas dos catadores, que preferem o trabalho individual, há uma concepção de que as pessoas unidas não trabalham tanto quanto uma sozinha. Os catadores que preferem o trabalho individual justificam esta opção a partir do trabalho independente de outras pessoas, ou seja, sentem-se livres para fazer o que desejam, sem que exista um controle de sua rotina, produtividade ou percurso que realizam. Conforme mencionado anteriormente, $45 \%$ dos catadores entrevistados já fizeram parte de associação de catadores. Entretanto a experiência frustrada parece ter influenciado na visão negativa sobre o trabalho coletivo para estes catadores. Nestes casos, constata-se que não há a compreensão sobre as vantagens do trabalho cooperado/ associativo, resultante das experiências frustradas que vivenciaram. Segundo Gonçalves-Dias (2009), os homens têm menor propensão ao trabalho coletivo e, ainda, possuem resistência à organização, em especial na categoria de catadores.

Entre os 36\% de catadores que preferem o trabalho coletivo, os motivos apresentados referem-se à possibilidade de divisão do trabalho, pela importância da representatividade, 
conforme destacado nas falas a seguir: "No coletivo é melhor, porque um ajuda o outro, é uma força maior" (mulher, 46 anos); "Porque se a gente trabalha em mais gente, é melhor. Uma andorinha não faz verão sozinha" (mulher, 44 anos).

Ao serem questionados sobre o que entendem por cooperativa ou associação, muitos catadores não souberam responder. Também, naqueles que estão inseridos em uma associação, observou-se insegurança na resposta. Algumas manifestações dos pesquisados ilustram estas dúvidas: "Associação é que nem nós temo no barracão, mas não sei dizer o que é isso bem certo" (homem, 67 anos). "É uma equipe, né, que trabalham junto e depois divide o que der de dinheiro. Eu acho que é assim" (mulher, 46 anos). "Associação é tipo uma irmandade, tudo se ajuda, cada um faz a sua parte. É tipo uma comunidade, tudo tem que te uma combinação, se ajudar" (homem, 46 anos).

Com base no que foi observado durante as entrevistas, é possível que os catadores vinculados à associação tenham dificuldades para responder o que significa trabalho coletivo, pelo fato de que, neste empreendimento, a cultura associativa não parece estar sendo disseminada aos integrantes do grupo. Inclusive, alguns associados se referem à associação como se ela tivesse dono, havendo uma confusão entre diretoria e proprietários da instituição. Princípios como autogestão, controle e acesso às informações financeiras e produtivas da associação não foram mencionados por esses catadores, integrados à referida associação. Desta forma, complementando todas as privações de liberdade já mencionadas até aqui nesta pesquisa, também na atuação coletiva em associação de catadores os entrevistados parecem não usufruir de seus direitos coletivos.

Assim, a partir deste conjunto de informações sobre os catadores de materiais recicláveis no município de Laranjeiras do Sul, Paraná, pôde-se averiguar que as condições precárias em que vivem Ihes impõem inúmeras privações de liberdade (SEN, 2010), dificultando o acesso às condições adequadas de vida.

Em geral, os catadores, priorizam (e precisam priorizar) a necessidade de sobrevivência (ROCHA, 2012). E isso pôde ser evidenciado nos catadores pesquisados: eles vislumbram satisfazer as suas necessidades primárias, mais imediatas. Neste contexto, a fim de que se possa falar em desenvolvimento, é necessário que esses indivíduos possam adquirir as capacidades para que a opção diante das oportunidades seja uma realidade. Entretanto, quando se visualiza que são precárias as condições de acesso à educação, saúde, trabalho e que essas não melhoram com o passar do tempo, inclusive mantendo os filhos na precariedade, a preocupação é ainda maior.

Na perspectiva de mudanças que são necessárias para os catadores, constata-se que não basta aguardar que sozinhos modifiquem sua realidade. Nestes casos, a privação de liberdade é tão severa que somente conseguirão melhorar suas condições quando houver auxílio externo. Neste contexto, há duas organizações importantes que podem e devem atuar no sentido de promover mudanças, são elas a gestão pública municipal e a universidade. A primeira, por intermédio das secretarias de saúde, educação, assistência social e meio ambiente, deve dar suporte aos catadores e suas famílias para que possam ter acesso aos recursos de saúde, educação, documentos, programas sociais. E a segunda, a universidade, por intermédio dos projetos, docentes e acadêmicos, pode auxiliar na realização de cursos voltados aos catadores ou na orientação quanto ao trabalho coletivo. Para além destas duas entidades, talvez, quando os catadores deixarem de ser invisíveis para a sociedade, esta possa também se comprometer a construir mudanças para as duras realidades identificadas. 


\section{CONSIDERAÇÕES FINAIS}

Nas condições do presente estudo, evidencia-se que os catadores de materiais recicláveis do município vivem em meio a muitas privações de liberdade, o que não difere da difícil realidade vivida por outros catadores do Brasil.

Constatou-se que a maior parte do grupo pesquisado vive em meio à pobreza, à falta de acesso a serviços de saúde e educação, apresenta condições insalubres de vida, trabalha grande número de horas por dia, não tem registro formal da atividade e recebe pouco pelo material coletado. Ainda, estes catadores de materiais recicláveis são explorados, discriminados e excluídos da sociedade, por sobreviverem daquilo que é descartado por ela.

Nesse sentido, é importante ressaltar a responsabilidade de quem está vinculado à gestão pública municipal, estadual, federal e à comunidade universitária, que podem contribuir para a emancipação dos catadores, seja na atuação individual, seja na atuação coletiva.

\section{REFERÊNCIAS}

BOSI, A. P. A organização capitalista do trabalho "informal". Revista Brasileira de Ciências Sociais, São Paulo, v. 23, n. 67, p. 101-16, jun. 2008.

BOTELHOL, L. L. R.; SCHERER, L.; SCHOMMER, J. A.; DIECHETI, H.; WUERGES, A. F. E. Catadores de materiais recicláveis no município de Cerro Largo (RS): perspectivas através do trabalho e o papel da ITCEESUFFS (incubadora tecnossocial de cooperativas e empreendimentos de economia solidária). Revista do Desenvolvimento Regional, Taquara, v. 14, n. 1, p. 59-77, jan./jun. 2017.

GONÇALVES-DIAS, S. L. F. Catadores: uma perspectiva de sua inserção no campo da indústria de reciclagem. 2009. 298 f. Tese (Doutorado em Ciência Ambiental) - Universidade de São Paulo, São Paulo, SP, 2009.

GOOGLE MAPS, 2015a. Disponível em: https://www.google.com.br/maps/dir/Get\%C3\%BAlio+Vargas,+Lara njeiras+do+Sul+-+Estado+de+Paran\%C3\%A1/-25.4032108,-52.4136392/@-25.4101895,-52.4197539,15z/ am=t/data $=$ !4m9!4m8!1m5!1m1!1s0x94efcbacb7dcdfb5:0x5b7572ead435ad43!2m2!1d-52.410132!2d25.4168575!1m0!3e0. Acesso em: 31 out. 2015.

GOOGLE MAPS, 2015b. Disponível em: https://www.google.com.br/maps/dir/-25.3934754,-52.4001141/25.4023928,-52.4131892/@-25.3985324,-52.4123818,16z/data=!4m3!4m2!3e0!5i2. Acesso em: 31 out. 2015.

MOVIMENTO NACIONAL DOS CATADORES DE MATERIAIS RECICLÁVEIS [MNCR]. A crise financeira e os catadores de materiais recicláveis. MNCR, Brasilia, 2010. Disponível em: http://www.mncr.org.br/artigos/acrise-financeira-e-os-catadores-de-materiais-reciclaveis. Acesso em: 28 maio 2015.

KIRCHNER, R. M.; SAIDELLES, A. P. F.; STUMM, E. M. F. Percepções e perfil dos catadores de materiais recicláveis de uma cidade do RS. Revista Brasileira de Gestão e Desenvolvimento Regional, Taubaté, v. 5, n. 3, p. 221-32, set./dez. 2009.

MAGALHÃES, B. J. Liminaridade e exclusão: os catadores de materiais recicláveis e suas relações com a sociedade brasileira. 2012. 131 f. Dissertação (Mestrado em Antropologia) - Universidade Federal de Minas Gerais, Belo Horizonte, MG, 2012.

MAGERA, M. Os empresários do lixo: um paradoxo da modernidade. Campinas, SP: Editora Átomo, 2003.

PORTAL BOLSA FAMÍLIA. Quem tem direito ao bolsa família? 2015. Disponível em: https:// programabolsafamilia.net/quem-tem-direito-ao-bolsa-familia/. Acesso em: 13 out. 2015. 
ROCHA, V. J. Política Pública de resíduos e o trabalho associativo dos catadores de material reciclável. In: ENCONTRO DE CIÊNCIAS SOCIAIS DO NORTE E NORDESTE E PRÉ-ALAS BRASIL, 15., 4 a 7 set. 2012, Teresina. Anais [...]. Teresina: UFPI, 2012.

SEN, A. Desenvolvimento como liberdade. São Paulo: Companhia de Letras, 2010.

SILVA, E. M. T.; VIRGOLIN, I. C.; ISRAEL, A. L. P.; VERISSIMO, F.; GUMA A. Traços do perfil dos catadores de materiais recicláveis do município de Cruz Alta/RS. In: SEMINÁRIO INTERINSTITUCIONAL DE ENSINO, PESQUISA E EXTENSÃO, 16., 4 a 6 out. 2011, Cruz Alta. Anais [...]. Cruz Alta: Unicruz, 2011.

WADMAN, M. Lixo: cenários e desafios - abordagens básicas para entender os resíduos sólidos. São Paulo: Cortez, 2010.

\section{Sobre as autoras:}

Grasieli de Fátima Rode: Mestre em Agroecologia e Desenvolvimento Rural Sustentável pela Universidade Federal da Fronteira Sul (UFFS). Graduada em Ciências Econômicas pela UFFS. E-mail: grasielirode@gmail.com, Orcid: http://orcid.org/0000-0002-9113-878X

Janete Stoffel: Doutora em Desenvolvimento Regional pela Universidade de Santa Cruz do Sul (UNISC). Mestre em Desenvolvimento Regional pela Universidade Regional do Noroeste do Estado do Rio Grande do Sul (UNIJUÍ). Graduada em Ciências Econômicas pela UNIJUÍ. Professora do curso de Ciências Econômicas e do programa de pós-graduação interdisciplinar em Agroecologia e Desenvolvimento Rural Sustentável na Universidade Federal da Fronteira Sul (UFFS). E-mail: janete.stoffel@uffs.edu.br, Orcid: http://orcid.org/0000-0003-0689-0414

Gabriela Silva Moura: Pós-doutora em Agroecologia e Desenvolvimento Rural Sustentável pela Universidade Federal da Fronteira Sul (UFFS). Doutora e mestre em Agronomia pela Universidade Estadual de Maringá (UEM). Graduada em Ciências Biológicas pelo Centro Universitário de Patos de Minas (UNIPAM). E-mail: bismoura@hotmail.com, Orcid: http://orcid.org/0000-0003-0404-2331 
